\title{
Host Adaptation Through Hybridization: Genome Analysis of Triticale Powdery Mildew Reveals Unique Combination of Lineage-Specific Effectors
}

\author{
Müller, Marion C ; Kunz, Lukas ; Graf, Johannes ; Schudel, Seraina ; Keller, Beat
}

\begin{abstract}
The emergence of new fungal pathogens through hybridization represents a serious challenge for agriculture. Hybridization between the wheat mildew (Blumeria graminis f. sp. tritici) and rye mildew (B. graminis f. sp. secalis) pathogens has led to the emergence of a new mildew form (B. graminis f. sp. triticale) growing on triticale, a man-made amphiploid crop derived from crossing rye and wheat, which was originally resistant to the powdery mildew disease. The identification of the genetic basis of host adaptation in triticale mildew has been hampered by the lack of a reference genome. Here, we report the 141.4-Mb reference assembly of triticale mildew isolate THUN-12 derived from long-read sequencing and genetic map-based scaffolding. All 11 triticale mildew chromosomes were assembled from telomereto-telomere and revealed that $19.7 \%$ of the hybrid genome was inherited from the rye mildew parental lineage. We identified lineage-specific regions in the hybrid, inherited from the rye or wheat mildew parental lineages, that harbor numerous bona fide candidate effectors. We propose that the combination of lineage-specific effectors in the hybrid genome is crucial for host adaptation, allowing the fungus to simultaneously circumvent the immune systems contributed by wheat and rye in the triticale crop. In line with this, we demonstrate the functional transfer of the SvrPm3 effector from wheat to triticale mildew, a virulence effector that specifically suppresses resistance of the wheat Pm3 allelic series. This transfer is the likely underlying cause for the observed poor effectiveness of several Pm3 alleles against triticale mildew and exemplifies the negative implications of pathogen hybridizations on resistance breeding. [Formula: see text] Copyright (C) 2021 The Author(s). This is an open access article distributed under the CC BY-NC-ND 4.0 International license .
\end{abstract}

DOI: https://doi.org/10.1094/mpmi-05-21-0111-sc

Posted at the Zurich Open Repository and Archive, University of Zurich

ZORA URL: https://doi.org/10.5167/uzh-212577

Journal Article

Published Version

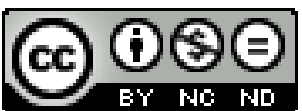

The following work is licensed under a Creative Commons: Attribution-NonCommercial-NoDerivatives 4.0 International (CC BY-NC-ND 4.0) License.

Originally published at:

Müller, Marion C; Kunz, Lukas; Graf, Johannes; Schudel, Seraina; Keller, Beat (2021). Host Adaptation Through Hybridization: Genome Analysis of Triticale Powdery Mildew Reveals Unique Combination of Lineage-Specific Effectors. Molecular Plant-Microbe Interactions, 34(12):1350-1357. 
DOI: https://doi.org/10.1094/mpmi-05-21-0111-sc 


\title{
Host Adaptation Through Hybridization: Genome Analysis of Triticale Powdery Mildew Reveals Unique Combination of Lineage-Specific Effectors
}

\author{
Marion C. Müller, Lukas Kunz, Johannes Graf, Seraina Schudel, and Beat Keller ${ }^{\dagger}$ \\ Department of Plant and Microbial Biology, University of Zurich, Zurich, Switzerland \\ Accepted 7 September 2021.
}

\begin{abstract}
The emergence of new fungal pathogens through hybridization represents a serious challenge for agriculture. Hybridization between the wheat mildew (Blumeria graminis f. sp. tritici) and rye mildew (B. graminis f. sp. secalis) pathogens has led to the emergence of a new mildew form (B. graminis f. sp. triticale) growing on triticale, a man-made amphiploid crop derived from crossing rye and wheat, which was originally resistant to the powdery mildew disease. The identification of the genetic basis of host adaptation in triticale mildew has been hampered by the lack of a reference genome. Here, we report the 141.4Mb reference assembly of triticale mildew isolate THUN-12 derived from long-read sequencing and genetic map-based scaffolding. All 11 triticale mildew chromosomes were assembled from telomere-to-telomere and revealed that $19.7 \%$ of the hybrid genome was inherited from the rye mildew parental lineage. We identified lineage-specific regions in the hybrid, inherited from the rye or wheat mildew parental lineages, that harbor numerous bona fide candidate effectors. We propose that the combination of lineage-specific effectors in the hybrid genome is crucial for host adaptation, allowing the fungus to simultaneously circumvent the immune systems contributed by wheat and rye in the triticale crop. In line with this, we demonstrate the functional transfer of the $\mathrm{SvrPm} 3$ effector from wheat to triticale mildew, a virulence effector that specifically suppresses resistance of the wheat $P m 3$ allelic series. This transfer is the likely underlying cause for the observed poor effectiveness of several $P m 3$ alleles against triticale mildew and exemplifies the negative implications of pathogen hybridizations on resistance breeding.
\end{abstract}

Keywords: avirulence factors, fungal effectors, fungus-plant interactions, genomics, hybridization, mechanisms of pathogenicity

${ }^{\dagger}$ Corresponding author: B. Keller; bkeller@botinst.uzh.ch

Funding: University Research Priority Program "Evolution in Action" of the University of Zürich and Schweizerischer Nationalfonds zur Förderung der Wissenschaftlichen Forschung (Swiss National Science Foundation) grant 310030B_182833.

*The $\boldsymbol{e}$-Xtra logo stands for "electronic extra" and indicates that supplementary materials are published online.

The author(s) declare no conflict of interest.

(c) (1) () () Copyright $\odot 2021$ The Author(s). This is an open access article distributed under the CC BY-NC-ND 4.0 International license.
The emergence of new fungal pathogens on crops poses a serious problem for agriculture. One mechanism by which fungal pathogens can adapt to a new host is hybridization, by which two different pathogen lineages recombine their gene complement, enabling them to infect a new host species (Thines 2019). Despite several reports of hybridizations in plant pathogens, host adaptation by hybridization is poorly understood and the genetic loci involved remain unidentified (Stukenbrock 2016).

A prominent example of a host adaptation through hybridization is the recent emergence of the triticale powdery mildew (Blumeria graminis f. sp. triticale) on the cereal crop triticale in the year 2001 (Walker et al. 2011). B. graminis f. sp. triticale was found to be the result of hybridization events between the highly host-specific fungal sublineages of wheat $(B$. graminis $\mathrm{f}$. sp. tritici) and rye (B. graminis $\mathrm{f}$. sp. secalis) powdery mildew (Menardo et al. 2016). The hybridization on the pathogen side mirrored the breeding history of its new host, which is an amphiploid resulting from a cross of the two cereal crops wheat (Triticum. sp.) and rye (Secale cereale) (Oettler 2005). Triticale has seen an increase in cultivation in the past decades, especially in Europe (Arseniuk 2014). Unfortunately, disease outbreaks of powdery mildew on triticale have increased in both number and severity, which corroborates the need for resistance breeding in this crop (Arseniuk 2014; Mascher et al. 2006; Kowalczyk et al. 2011).

Previous analyses of the triticale powdery mildew hybrid pathogen were based on the wheat mildew reference genome (Menardo et al. 2016; Praz et al. 2018). This approach suffers from its bias to the gene content of one of the parental lineages of the hybrid. This is particularly relevant because effectorssmall, secreted proteins that are encoded by hundreds of genes in powdery mildew genomes-reside in highly dynamic gene clusters that often show copy number variation or lineagespecific expansions (Frantzeskakis et al. 2018; Menardo et al. 2017; Müller et al. 2019). Due to their dual role in infection as putative virulence factors suppressing the host defenses as well as avirulence factors recognized by major resistance genes, effector genes represent prime candidates for host-specificity factors (Li et al. 2020). In this study, we present a chromosomescale assembly of triticale powdery mildew that will lay the foundation to understand host adaptation through hybridization in the cereal powdery mildew pathosystem.

We sequenced B. graminis f. sp. triticale isolate THUN-12 using PacBio technology to a sequencing depth of $180 \times$ to establish a reference assembly of the hybrid powdery mildew (Supplementary Table S1). The resulting assembly was $141.4 \mathrm{Mb}$ in size and consisted of 51 contigs. We used the previously described scaffolding method based on the genetic map of the 
fully sequenced mapping population of THUN-12 $\times$ B. graminis f. sp. tritici Bgt_96224 (Müller et al. 2019) to scaffold the contigs into 11 chromosomes (Supplementary Table S2). In all, three of the 11 chromosomes, namely, Chr-03, Chr-06, and Chr-10, were assembled in a single contig in the THUN-12 assembly. The remaining chromosomes were scaffolded with a maximum of three scaffold gaps. In addition, the genetic map allowed us to correct three assembly errors, in which chromosome arms originating from different chromosomes were fused in the centromeric regions. With a transposable element content of $69.4 \%$, the $B$. graminis f. sp. triticale genome exhibits a characteristic genome organization with high repeat content, reminiscent of other sequenced B. graminis isolates (Frantzeskakis et al. 2018; Müller et al. 2019). We found a single region per chromosome with a distinct transposable element content consisting of nonlong-terminal-repeat retrotransposons (Supplementary Fig. S1). These regions correspond to the centromeres that were previously identified in Bgt_96224 based on the absence of recombination and their low gene density, as well as the presence of specific centromeric repeats in certain cases (Müller et al. 2019). In addition, we found stretches of telomeric repeats TAACCC at all ends of the 11 chromosomes (Supplementary Fig. S1). The presence of telomeres and the centromere on each chromosome together with the low number of scaffold gaps indicates high completeness of all 11 chromosomes resolved in the B. graminis f. sp. triticale assembly. This represents a significant improvement to previous high-quality assemblies of the B. graminis species, which still contain hundreds of gaps or unresolved chromosomal regions (Frantzeskakis et al. 2018; Müller et al. 2019).

The high-quality genome of THUN-12 allowed us to study the signature of hybridization between $B$. graminis $\mathrm{f}$. sp. tritici and $B$. graminis f. sp. secalis at the chromosomal level. As described by Menardo et al. (2016), we used fixed polymorphisms between B. graminis f. sp. secalis and B. graminis f. sp. tritici to attribute genomic segments in THUN-12 to the two parental sublineages (Menardo et al. 2016). We found that $80.3 \%$ of the THUN-12 genome was inherited from wheat mildew and $19.7 \%$ was inherited from rye mildew (Fig. 1; Supplementary Table S2). The observed higher percentage of segments with wheat mildew origin in the THUN-12 isolate is consistent with the previously proposed scenario, in which the first ryewheat mildew hybrids backcrossed to wheat mildew after the initial hybridization event (Menardo et al. 2016). During meiosis, at least one crossover takes place between homologous chromosomes (Marston and Amon 2004). Indeed, we found at least one recombination event between wheat and rye mildew per chromosome, suggesting efficient chromosomal pairing in all chromosomes between the two parental lineages during the initial hybridization. Strikingly, the size of segments inherited form B. graminis f. sp. secalis varied considerably and proportional contribution to chromosomes ranged from $6.0 \%$ on Chr-09 to a maximum of $40.9 \%$ on Chr-04 (Fig. 1; Supplementary Table $\mathrm{S} 2$ ). In addition, the location of the $B$. graminis f. sp. secalis segments is highly variable between chromosomes; for instance, 8 of the 11 chromosomes inherited at least one telomeric sequence form $B$. graminis f. sp. secalis. In contrast, Chr-07 contains a single, larger segment inherited from $B$. graminis $\mathrm{f}$. sp. secalis that overlaps with the genetic centromere. The centromeres of all other chromosomes were inherited from $B$. graminis f. sp. tritici. To what degree the differential proportion of B. graminis $\mathrm{f}$. sp. secalis segments per chromosome are the result of differential contribution to host adaptation or purely stochastic based on the limited amount of recombination between the parental strains remains to be determined in further studies.

The availability of the hybrid THUN-12 genome and the previously published chromosome-scale assembly of the wheat mildew Bgt_96224 (Müller et al. 2019) allowed the comparison of the hybrid genome to the wheat mildew parental lineage. Upon whole-genome alignment of the two genomes (Supplementary Fig. S2A) using the MUMmer software (Kurtz et al. 2004), $99.26 \%$ of the THUN-12 genome was aligned to the Bgt_96224 genome. We observed a high colinearity across the 11 chromosomes in $B$. graminis f. sp. tritici-inherited regions as well as in the 27.7-Mb of sequence originating from $B$. graminis f. sp. secalis (Supplementary Fig. S2A). The analysis identified only a few $(<20)$ regions with major rearrangements, most of which overlap with the genetic centromeres (Supplementary Fig. $\mathrm{S} 2 \mathrm{~A}$ ). Due to their repetitive nature, rearrangements and rapid sequence divergence is to be expected in the centromeres. However, it should be noted that the centromeres consist exclusively of repetitive elements and, therefore, are often not completely resolved despite the long-read sequencing technology and, thus, the identified rearrangements could represent assembly artifacts (Müller et al. 2019). In addition, we identified a large inversion on Chr-02 (600 kb). Using BAC-end sequencing data, we showed that the inversion was the result of scaffolding error that resulted in the wrong orientation of a contig in the Bgt_96224 genome and, therefore, does not represent a real rearrangement (Supplementary Fig. S2B). The most interesting major difference between the genomes is a telomeric region of Chr-11 that is absent in the assembly of Bgt_96224 (Supplementary Fig. S2) and, therefore, represents a candidate lineage-specific region in THUN-12 which was inherited from B. graminis $\mathrm{f}$. sp. secalis (see below). When we considered smaller rearrangements $(>1$ $\mathrm{kb}$ or $<10 \mathrm{~kb}$ ) predicted by the MUMmer software, we found evidence for alignment breaks that constitute inversions, gaps, and duplications on all chromosomes (Supplementary Table S3). Segments inherited from $B$. graminis $\mathrm{f}$. sp. secalis were significantly enriched for such rearrangements compared with segments inherited from B. graminis f. sp. tritici, which is consistent with the divergence of the two fungal lineages approximately 160,000 to 250,000 years ago (Supplementary Table S3) (Menardo et al. 2016). Due to the predominance of small-scale rearrangements identified by comparison with $B$. graminis f. sp. tritici, we concluded that the two parental formae speciales of the hybrid have a very similar overall genome structure. This is consistent with our findings in the experimental population Bgt_96224 $\times$ THUN-12, for which we found no impairment of recombination in segments inherited from B. graminis f. sp. secalis (Müller et al. 2019). Therefore, we propose that the high similarity of the two genomes provided the basis for the successful hybridization of B. graminis f. sp. secalis and B. graminis $\mathrm{f}$. sp. tritici that gave rise to the first $B$. graminis $\mathrm{f}$. sp. triticale hybrids and that the occurrence of hybridization of these lineages was mainly limited by suitable host plants in the past.

The process of hybridization allows the combination of genes or genomic regions that are normally present only in one particular fungal lineage but absent in the other. In numerous fungal plant pathogens, host adaptation has been attributed to the occurrence of lineage-specific effector proteins acting as virulence factors (i.e., allowing growth on the particular host) or avirulence factors (i.e., preventing growth due to recognition by hostspecific immune receptors). To identify putative effector genes in the $B$. graminis f. sp. triticale hybrid, we performed a de novo gene annotation based on the previously published proteins of $B$. graminis f. sp. tritici and B. graminis f. sp. hordei. This resulted in the annotation of 7,993 genes, including 1,011 candidate effectors that were subsequently assigned to the previously described Blumeria candidate effector families (Supplementary Note S1) (Müller et al. 2019). To test for the parental contribution to the gene content of the hybrid, we determined for each gene whether it is encoded in a segment derived from wheat or rye mildew. Consistent with the proportion of the origin of 
genomic segments, we found that, in total, $20 \%$ of all genes in THUN-12 were encoded within a segment of B. graminis $\mathrm{f}$. sp. secalis. To define lineage-specific effectors, we used genomic coverage based on resequencing data from $B$. graminis f. sp. tritici or B. graminis f. sp. secalis isolate to predict the absence of the THUN-12 candidate effectors in all isolates within one parental forma specialis (Supplementary Note S2; Supplementary Figs. S3 and S4). We identified five loci containing candidate, lineage-specific effector genes inherited from B. graminis secalis in the telomeric regions of Chr-01, Chr-04, and Chr-11 and on the chromosome arms of Chr-08 and Chr-09 (Fig. 1). Upon comparison with the Bgt_96224 genome, we could confirm the absence of these effector genes within the wheat mildew lineage (Fig. 2; Supplementary Note S3). For instance, the $B$. graminis $\mathrm{f}$. sp. secalis lineage-specific region on $\mathrm{Chr}-01$ in THUN-12 contains a threefold tandem duplication of two effectors belonging to families E135 and E001, respectively, whereas the corresponding region in Bgt_96224 contains only one gene each (Fig. 2A; Supplementary Fig. S5B). On the B. graminis f. sp. secalis-inherited region of Chr-04, we found a cluster of the E029 effector family with nine members in THUN-12 and six members in Bgt_96224. Therefore, this cluster predates the split between $B$. graminis f. sp. secalis and B. graminis f. sp. tritici but rearrangements within the cluster have led to three lineagespecific effectors in B. graminis f. sp. secalis (Fig. 2B). The third example represents the abovementioned lineage-specific region on THUN-12 Chr-11, which was found to be partially absent from the Bgt_96224 assembly. The region contains six candidate effector genes, of which three belong to family E003 and are lineage specific for $B$. graminis secalis (Fig. 2C). The remaining two $B$. graminis f. sp. secalis-inherited regions on Chr-08 and Chr-09 contained a single effector gene present in THUN-12 but absent from Bgt_96224 belonging to E004 and E001, respectively (Fig. 2D and E). It is worth noting that
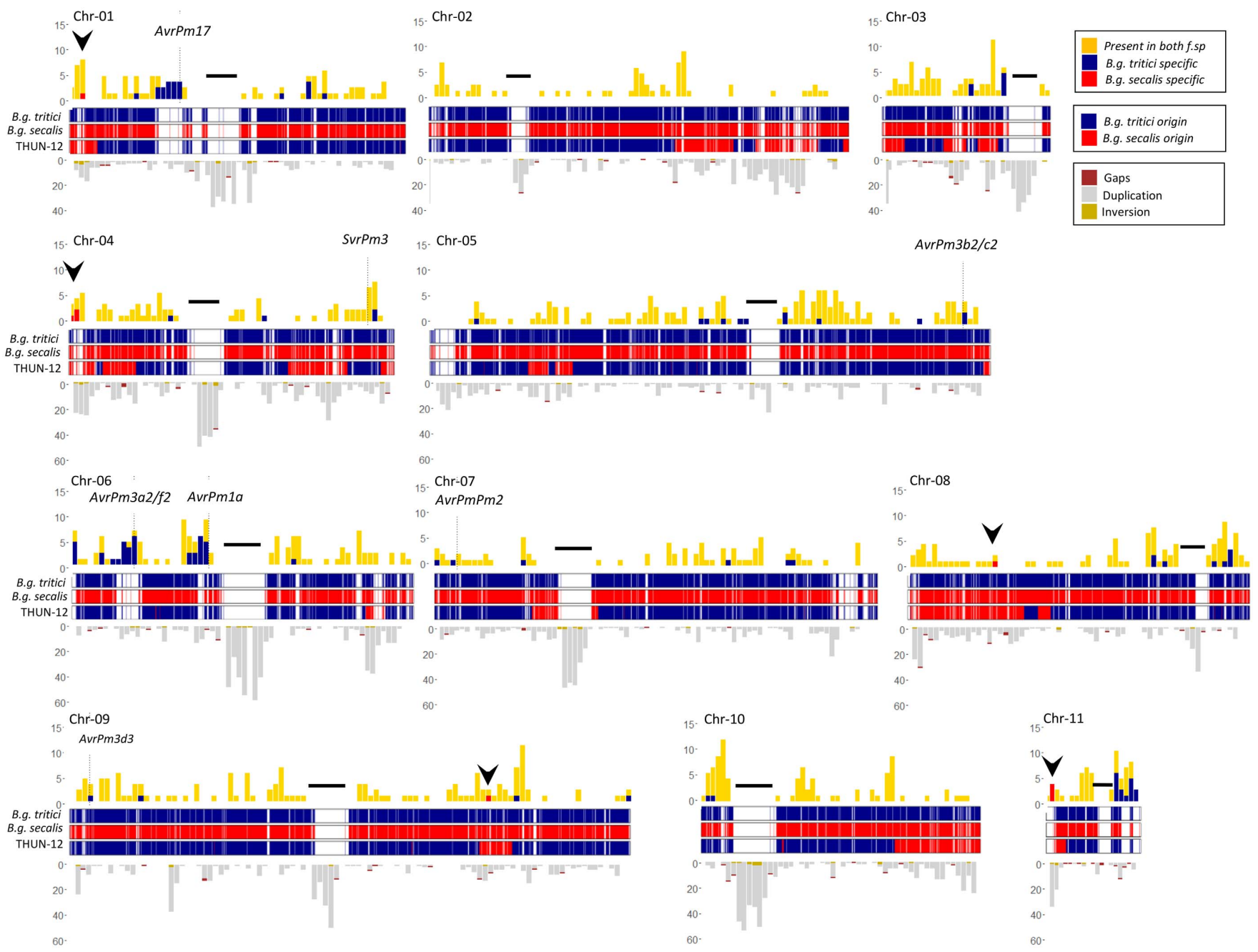

Fig. 1. Overview of the 11 chromosomes of Blumeria graminis f. sp. triticale THUN-12. The first track shows the distribution of candidate effector genes along the 11 chromosomes. Candidate effectors present in both parental species f. sp. tritici and f. sp. secalis are indicated in yellow; candidate, lineage-specific effector genes of $B$. graminis f. sp. secalis isolates are indicated in red; and candidate, lineage-specific effector genes of $B$. graminis $\mathrm{f}$. sp. tritici are indicated in blue. Black arrowheads indicate the position of regions for which a lineage-specific signal was detected and that are depicted in detail in Figure 2. Genomic positions of avirulence effectors are indicated. The second track indicates the genomic origin of the THUN-12 sequence, based on fixed polymorphisms between B. graminis f. sp. secalis and B. graminis f. sp. tritici. Single-nucleotide polymorphism (SNPs) originating from B. graminis f. sp. secalis are indicated in red and SNPs originating from B. graminis f. sp. tritici are represented in blue. For each chromosome, the position of the genetic centromere is indicated by a black bar. The third track indicates number of putative alignment breaks between $B$. graminis $\mathrm{f}$. sp. triticale THUN-12 and B. graminis f. sp. tritici Bgt_96224 based on whole-genome alignment of the chromosome-scale assemblies of the two formae speciales by the MUMmer software. Putative rearrangements were filtered and only rearrangements bigger than $1 \mathrm{~kb}$ and smaller than $10 \mathrm{~kb}$ are depicted. The alignment breaks were depicted according to the prediction of the MUMmer software as follows: brown indicates putative gaps, gray indicates putative duplications, and yellow indicates putative inversions. 
several of the identified $B$. graminis f. sp. secalis lineagespecific candidates exhibit similarities with validated virulence or avirulence factors in B. graminis f. sp. tritici and B. graminis f. sp. hordei (Supplementary Note S4). For example, several candidates belong to a group of small, highly expressed candidate effector families (termed group 1 effectors) harboring most of the virulence and avirulence factors in the Blumeria genus identified to date (Müller et al. 2019). Similarly, numerous genes are predicted to exhibit structural similarities (RNAse-like fold) to cloned avirulence genes and virulence factors (Supplementary Fig. S5) (Bauer et al. 2021). Most importantly, several lineagespecific candidates exhibit very high expression levels in THUN-12 during the crucial phase of haustoria establishment on infected triticale leaves (cultivar Timbo) at 2 days postinfection (Supplementary Fig. S5), a hallmark of avirulence factors in wheat mildew (Bourras et al. 2019).

Using the same coverage-based approach, we also identified several regions containing candidate effector genes absent from the $B$. graminis f. sp. secalis lineage. We found four loci with strong signatures of $B$. graminis $\mathrm{f}$. sp. tritici lineage specificity on Chr-01, Chr-06, and Chr-11 (Fig. 1). Strikingly, three loci overlapped with the known $B$. graminis f. sp. tritici gene clusters harboring AvrPm17 (Chr-01), AvrPm3 ${ }^{a 2 / f 2}$ (Chr-06), and AvrPmla (Chr-06) (Supplementary Note S5). It was previously hypothesized that the strong selection pressure exerted by corresponding resistance genes in wheat has led to effector cluster expansions in these regions in the $B$. graminis f. sp. tritici lineage (Hewitt et al. 2021; Müller et al. 2021; Müller et al. 2019). The fourth region showing a high density of $B$. graminis $\mathrm{f}$. sp. tritici-specific effectors on Chr-11 of THUN-12 might consequently harbor a thus-far-unidentified avirulence gene. Interestingly, the $B$. graminis $\mathrm{f}$. sp. tritici lineage-specific effectors on Chr-11 belong to the E003 family. Gene members of the same family are also present in the $B$. graminis f. sp. tritici-specific locus on Chr-01 (AvrPm17) (Müller et al. 2021) and the B. graminis f. sp. secalis-specific region on the other arm of Chr-11 (see above). Thus, the E003 family members represent prime candidates for effectors involved in host adaptation on triticale. In summary, we found that the $B$. graminis f. sp. triticale hybrid contains lineage-specific effectors inherited from both parental lineages. We hypothesize that these regions play a role in host adaptation and virulence of triticale powdery mildew on the new

A
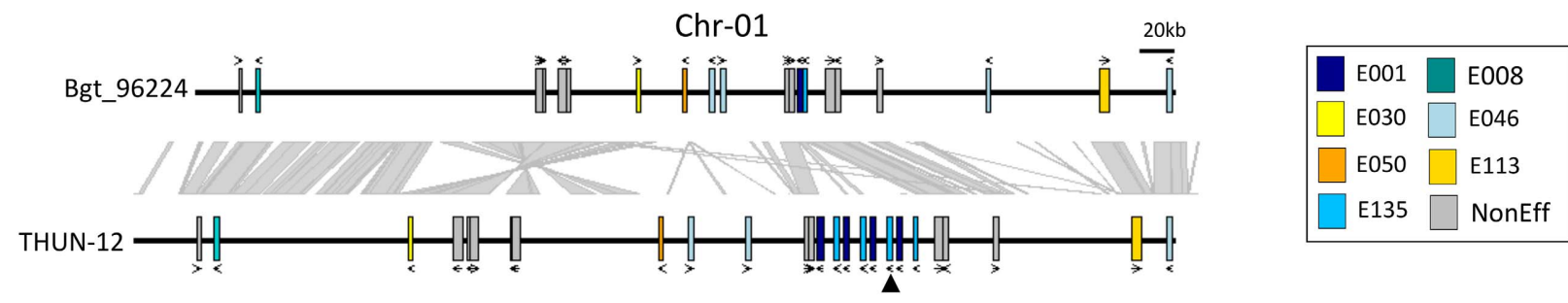

B
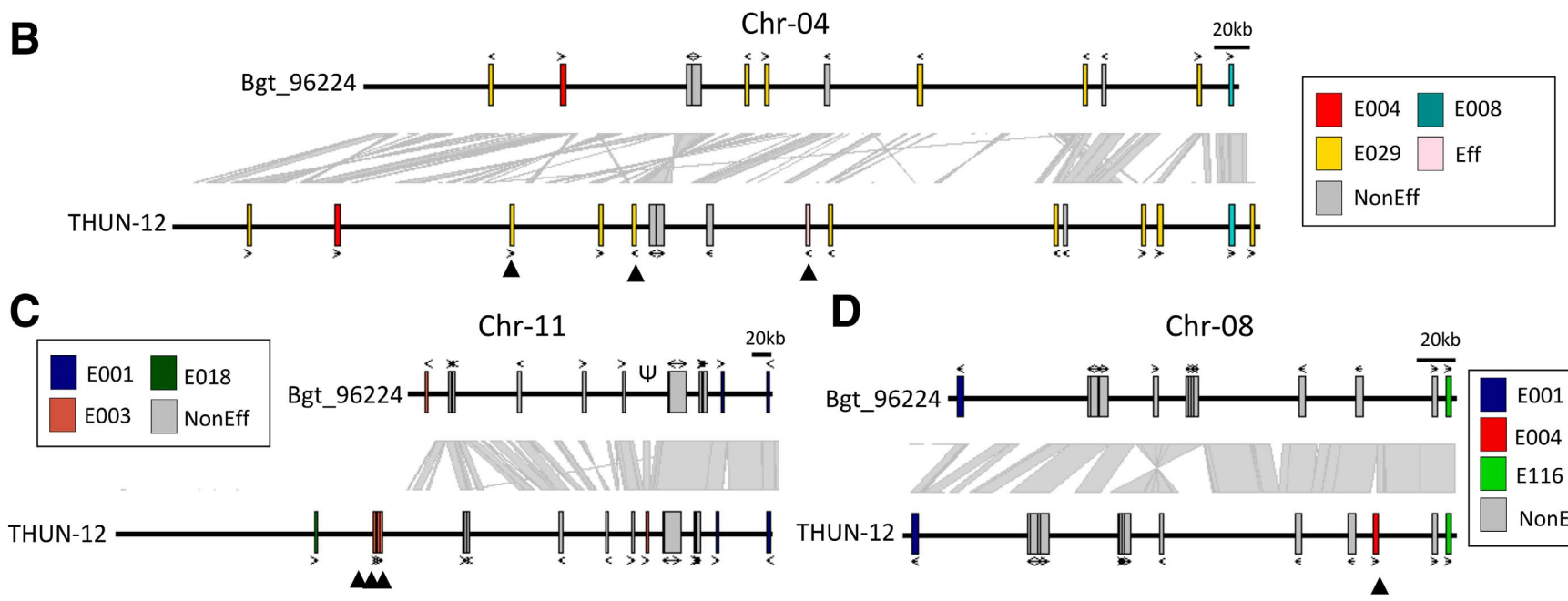

D
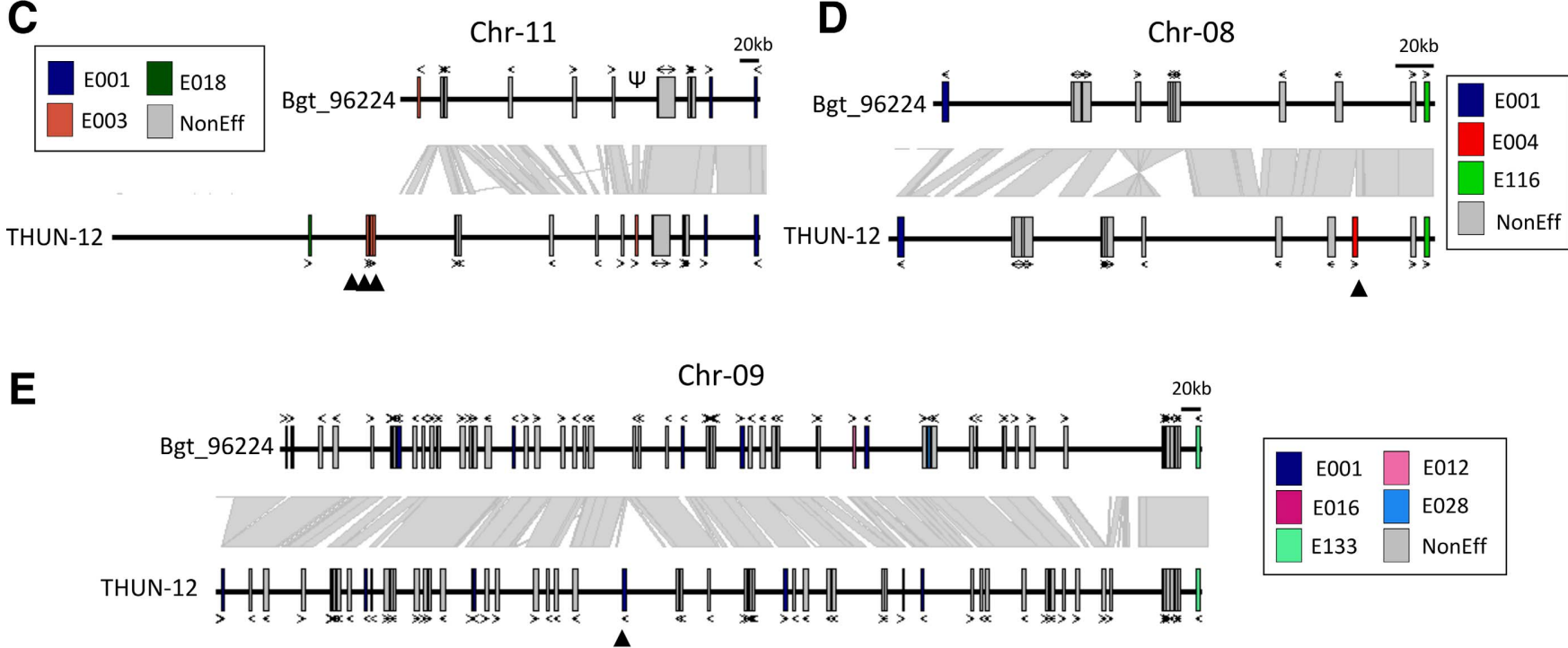

Fig. 2. Identification of lineage-specific candidate effector genes in THUN-12 inherited from the Blumeria graminis f. sp. secalis parental isolate. Candidate effectors genes are indicated by colored boxes according to their candidate effector family (Müller et al. 2019). Noneffector genes representing single-copy orthologs determined by the OrthoFinder software are indicated by gray boxes. Eff indicates an effector gene not assigned to a candidate effector family. Gene direction is indicated above or below the gene. Colinearity as determined by the MUMmer software is indicated by gray rectangles between the gene tracks. Genes for which a lineage-specific signal was detected are marked by a black arrowhead. Telomeric ends of A, Chr-01; B, Chr-04; and $\mathbf{C}$, Chr-11; and genomic loci within the chromosome arms of $\mathbf{D}, \mathbf{C h r}-08$ and $\mathbf{E}, \mathbf{C h r}-09$. The full description on the identification of the lineage-specific candidate effector is available in Supplementary Note S3. 
host triticale, enabling the fungus to cope with both the rye and wheat immune system, simultaneously present in triticale.

As described above, three loci with strong evidence for a lineage-specific expansion in THUN-12 correspond to the previously identified AvrPmla, AvrPm17, and $A v r P m 3^{a 2 / f 2}$ loci in wheat mildew. In addition, the regions corresponding to the other cloned wheat mildew avirulence genes-namely AvrPm2, $A v r P m 3^{b 2 / c 2}$, and $A v r P m 3^{d 3}$-are also encoded in segments from wheat mildew in THUN-12. Therefore, the genomes of THUN-12 and Bgt_96224 provided us with a unique opportunity to compare all of the previously described wheat mildew avirulence loci in two high-quality genomes (Fig. 3A to F). This comparison allowed us to confirm previous observations based on short-read sequencing data. For instance, THUN-12 contains three $A v r P m 3^{a 2 f 2}$ genes, as we have previously predicted for many $B$. graminis f. sp. tritici isolates based on genomic coverage (Müller et al. 2019). Furthermore, the $A v r P m 3^{b 2 / c 2}$ locus contains an additional candidate effector in THUN-12 that is pseudogenized in Bgt_96224 by a transposable element insertion (Bourras et al. 2019), whereas the $A v r P m 3^{d 3}$ locus exhibits several small-scale insertions surrounding the avirulence gene. Also, THUN-12 contains the known deletion covering the AvrPm 2 gene, a deletion that is adaptive because it allows mildew to overcome Pm2-mediated resistance in wheat (Praz et al. 2017). In addition, we could detect new variations previously undetected such as a small inversion affecting an effector in the AvrPmla locus as well as a nonallelic gene conversion event in the newly identified AvrPm17 paralogous effector pair (Müller et al. 2021). Strikingly, despite the dynamic nature of these avirulence loci, the THUN-12 isolate, with the exception of the deleted AvrPm2, encodes for the avirulent allele of all five avirulence genes. It was previously proposed that avirulence genes in powdery mildew exert an important pathogenicity function on wheat (Bourras et al. 2019; McNally et al. 2018). Therefore, we hypothesize that the functional conservation of $B$. graminis f. sp. tritici avirulence effectors in $B$. graminis $\mathrm{f}$. sp. triticale provides the hybrid pathogen with increased pathogenicity capacity, at least in the absence of corresponding resistance genes in triticale.

To test the functionality of the $B$. graminis f. sp. tritici avirulence genes in the hybrid genetic background, we analyzed their expression during early infection on triticale at the time point of haustorium formation (i.e., $48 \mathrm{~h}$ postinfection). Similar to the situation in wheat mildew, the avirulence genes are consistently among the highest expressed genes in THUN-12 (Fig. 4A) (Mueller et al. 2021). In line with this, THUN-12 is avirulent on wheat lines containing Pmla, Pm17, Pm3a, Pm3b, and Pm3d (Fig. 4B). We however observed virulent phenotypes of THUN12 on near-isogenic lines containing $P m 3 f$ (weak allele of $P m 3 a$ ) and $P m 3 c$ (weak allele of $P m 3 b$ ), despite the presence of $A v r P m 3^{a 2 / f 2}$ and $A v r P m 3^{b 2 / c 2}$ (Fig. 4B). To resolve this phenotypic or genotypic discrepancy, we performed quantitative trait loci (QTL) mapping based on 55 progeny of the Bgt_96224 $\times$ THUN-12 population on the Pm3c-containing wheat line Sonora/8*CC. We found a single QTL (logarithm of the odds [LOD] = 9.44) on Chr-04 (Fig. 4C) that corresponds to the previously described SvrPm3 locus in wheat mildew (Bourras et al. 2015; Parlange et al. 2015). SvrPm3 encodes an effector that

A

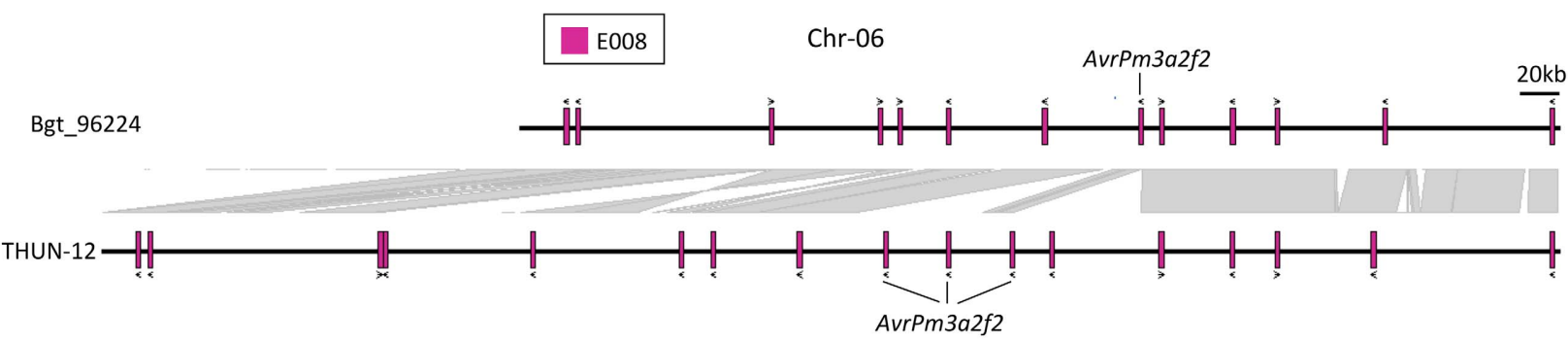

B
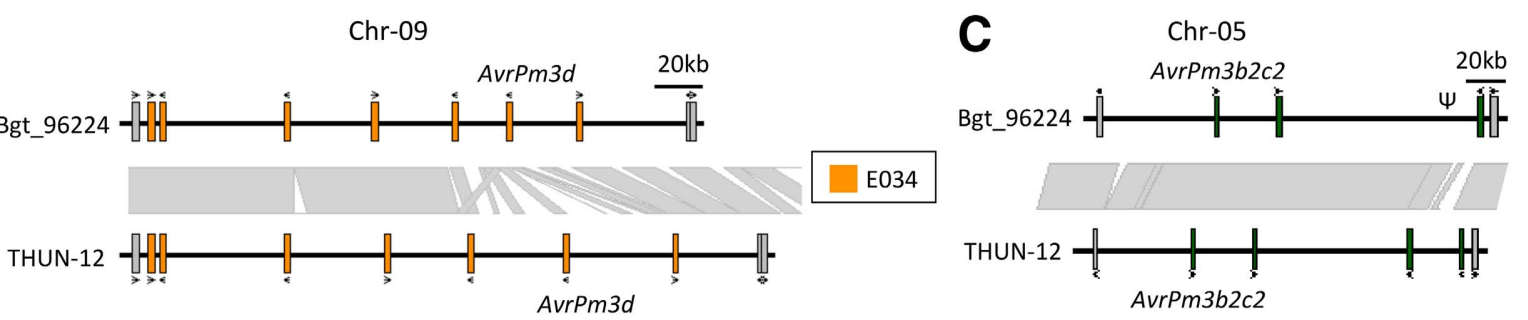

E018
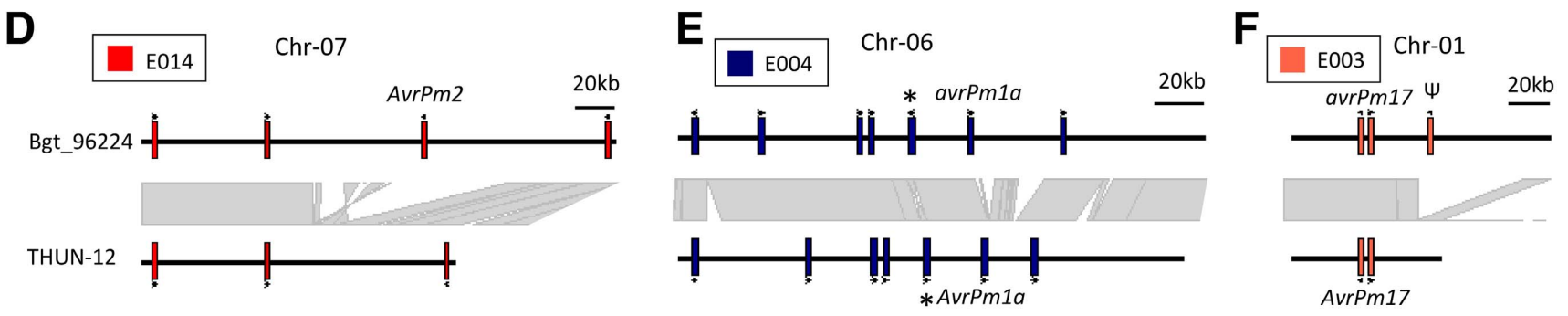

Fig. 3. Comparison of six avirulence loci identified in wheat mildew between the Blumeria graminis f. sp. triticale isolate THUN-12 and B. graminis tritici isolate Bgt_96224. A to F, Hybrid mildew THUN-12 inherited all of these loci from the B. graminis f. sp. tritici parental lineage. Genes are indicated by a box and gene orientation is indicated above or beneath the box. Genome aligned as determined by the MUMmer software is indicated by gray rectangles between the gene tracks. Effector genes are indicated by colored boxes according to their candidate effector family (Müller et al. 2019). Gray boxes indicate noneffector genes. Loci were manually checked and low-confidence genes (i.e., pseudogenes and transposable elements) were removed. Asterisks in panel $\mathrm{E}$ indicate a small inversion affecting a candidate effector gene. 
suppresses resistance mediated by $P m 3 a$ to $P m 3 f$. Indeed, THUN-12 contains the active $\operatorname{SvrPm3}$ haplovariant, again encoded by a wheat mildew segment (Figs. 1 and 4D; Supplementary Fig. S6), whereas Bgt_96224 encodes the inactive allele (Bourras et al. 2015; Parlange et al. 2015). Thus, the virulent phenotype of THUN-12 on the weak $P m 3 c$ and Pm3f alleles (Brunner et al. 2010) can be explained by the presence of the SvrPm3 suppressor gene, efficiently masking recognition of $A v r P m 3^{a 2 / f 2}$ and $A v r P m 3^{b 2 / c 2}$ and thereby demonstrating the functionality of a major wheat mildew virulence factor in the hybrid genetic background. Because $B$. graminis f. sp. secalis encodes for an inactive SvrPm3 haplovariant (Bourras et al.
2019), the active variant could only be inherited from B. graminis f. sp. tritici. The presence of the active $\operatorname{SvPPm} 3$ in the triticale mildew population likely has implications for triticale breeding. It was previously demonstrated that SvrPm3-based suppression is quantitative and that isolates expressing $\mathrm{SvrPm} 3$ to very high levels are also able suppress the stronger $P m 3 a$ and $P m 3 b$ alleles (Bourras et al. 2015, 2019). Therefore, the presence of $\mathrm{SvrPm3}$ in the B. graminis $\mathrm{f}$. sp. triticale population potentially renders the entire $P m 3$-allelic series ineffective for controlling mildew on triticale. Indeed, previous studies have found virulence proportion of over $40 \%$ toward several Pm3 alleles in the triticale powdery mildew populations of Poland,
A

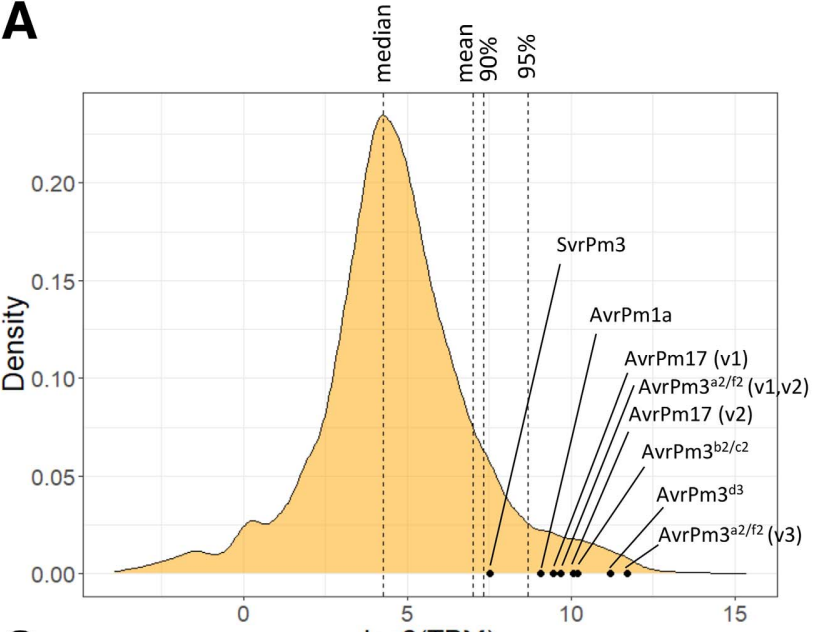

B

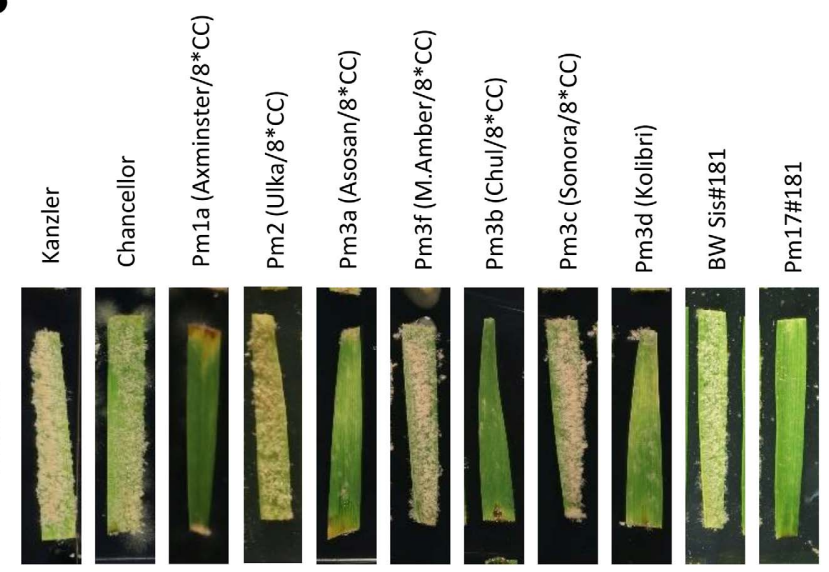

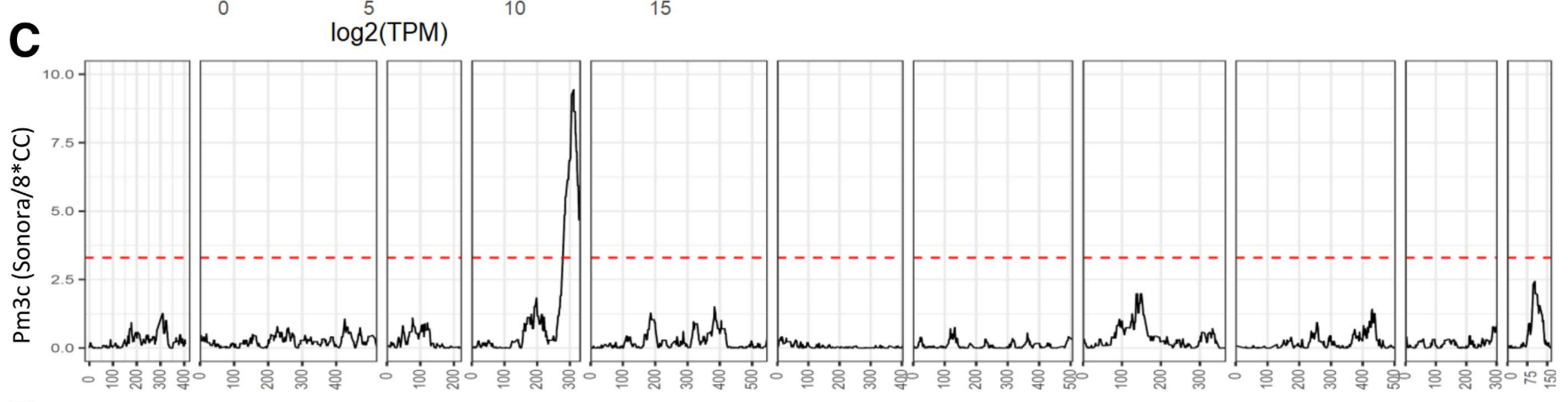

D
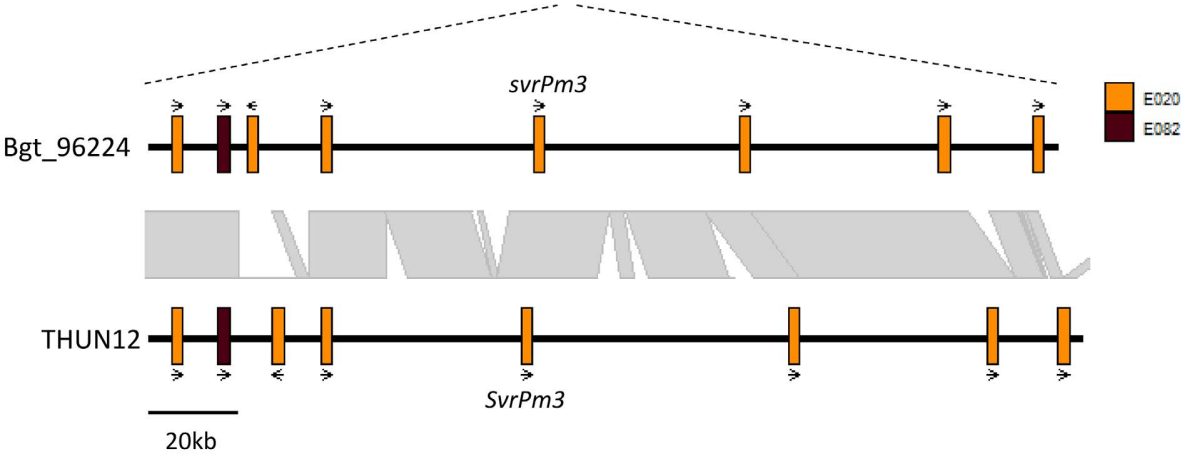

Fig. 4. Analysis of avirulence genes in Blumeria graminis f. sp. triticale THUN-12. A, Summary of gene expression of all genes in isolate THUN-12 at 2 days postinfection (dpi) on susceptible triticale cultivar Timbo. Gene expression is displayed as $\log _{2}$-transformed TPM (transcripts per million) values. Values for avirulence genes are indicated as black dots. There are several gene copies of AvrPm17 and AvrPm3 ${ }^{a 2 / f 2}$ in the THUN-12 genome. AvrPm17 gene copies differ by two single-nucleotide polymorphisms (SNPs) and are represented separately. Two of the $A v r P m 3^{a 2 / f 2}$ copies are identical and represented (v1 and v2) as a single data point, whereas the third copy carries a single synonymous SNP (v3) and is represented separately. B, Phenotypes of isolate THUN-12 at $10 \mathrm{dpi}$ on wheat differential lines or transgenic lines containing Pm17 in the Bobwhite background C, Result of the single-interval quantitative trait loci mapping approach, based on 55 randomly selected progeny of the mapping population Bgt_96224 $\times$ THUN-12 on the Pm3c containing near-isogenic line Sonora/8*CC. The black line indicates the logarithm of the odds (LOD) score of the association. The dashed red line indicates the significance threshold estimated by 1,000 permutations. D, Region corresponding to the 1.5-LOD interval in the two genomes of isolates Bgt_96224 and THUN-12. Genes are indicated by colored boxes. Gene orientation is indicated by arrows. Members of different candidate effector families are represented by different colors as indicated. 
France, and Belgium (Czembor et al. 2013, 2014; Troch et al. 2013). We propose that these results can be explained by the presence of the active $\mathrm{SvrPm3}$ in these populations. Although rye is considered an excellent source of powdery mildew resistance (Crespo-Herrera et al. 2017), resistance gene cloning has focused on wheat. To date. only two rye resistance genes, $P m 8$ and $P m 17$, both overcome by triticale powdery mildew, were cloned (Hurni et al. 2013; Singh et al. 2018; Troch et al. 2012). Crespo-Herrera et al. (2017) list an additional $10 \mathrm{Pm}$ loci originating from rye that could potentially be tested for resistance against triticale, and we propose that matching mildew resources should be generated to allow rapid identification of the corresponding avirulence genes.

In summary, we present a chromosome-scale genome assembly of the $B$. graminis f. sp. triticale hybrid pathogen based on significant advances in long-read sequencing technology and a high-resolution genetic map, thereby allowing a molecular analysis of the hybrid genome structure of a fungal plant pathogen. The B. graminis f. sp. triticale genome is defined as a mosaic between two highly collinear parental genomes of wheat and rye powdery mildew and includes several lineage-specific regions harboring highly expressed candidate effector genes. The reference genome of $B$. graminis $\mathrm{f}$. $\mathrm{sp}$. triticale provides the basis for future identification and functional validation of virulence factors involved in host adaptation on triticale. Furthermore, we provide evidence that avirulence and suppressor genes identified in wheat mildew are fully functional in $B$. graminis $\mathrm{f}$. sp. triticale and thereby exemplify the importance of genomic analyses of plant pathogens for resistance breeding in triticale. We propose to preemptively combine genomic resources and pathogen diversity analyses to increase the efficiency of resistance breeding in triticale and beyond.

\section{LITERATURE CITED}

Arseniuk, E. 2014. Triticale biotic stresses-An overview. Commun. Agric. Appl. Biol. Sci. 79:82-100.

Bauer, S., Yu, D., Lawson, A. W., Saur, I. M. L., Frantzeskakis, L., Kracher, B., Logemann, E., Chai, J., Maekawa, T., and Schulze-Lefert, P. 2021. The leucine-rich repeats in allelic barley MLA immune receptors define specificity towards sequence-unrelated powdery mildew avirulence effectors with a predicted common RNase-like fold. PLoS Pathog. 17:e1009223.

Bourras, S., Kunz, L., Xue, M., Praz, C. R., Müller, M. C., Kälin, C., Schläfli, M., Ackermann, P., Flückiger, S., Parlange, F., Menardo, F., Schaefer, L. K., Ben-David, R., Roffler, S., Oberhaensli, S., Widrig, V., Lindner, S., Isaksson, J., Wicker, T., Yu, D., and Keller, B. 2019. The AvrPm3-Pm3 effector-NLR interactions control both race-specific resistance and host-specificity of cereal mildews on wheat. Nat. Commun. 10:2292.

Bourras, S., McNally, K. E., Ben-David, R., Parlange, F., Roffler, S., Praz, C. R., Oberhaensli, S., Menardo, F., Stirnweis, D., Frenkel, Z., Schaefer, L. K., Flückiger, S., Treier, G., Herren, G., Korol, A. B., Wicker, T., and Keller, B. 2015. Multiple avirulence loci and allelespecific effector recognition control the $P m 3$ race-specific resistance of wheat to powdery mildew. Plant Cell 27:2991-3012.

Brunner, S., Hurni, S., Streckeisen, P., Mayr, G., Albrecht, M., Yahiaoui, N., and Keller, B. 2010. Intragenic allele pyramiding combines different specificities of wheat Pm3 resistance alleles. Plant J. 64:433-445.

Crespo-Herrera, L. A., Garkava-Gustavsson, L., and Åhman, I. 2017. A systematic review of rye (Secale cereale L.) as a source of resistance to pathogens and pests in wheat (Triticum aestivum L.). Hereditas 154:14.

Czembor, H., Doraczyńska, O., and Czembor, J. 2013. Resistance of triticale cultivars to powdery mildew (Blumeria graminis ff. ssp.) occurring in Poland. Biul. IHAR 267:3-16.

Czembor, H. J., Domeradzka, O., Czembor, J. H., and Mankowski, D. R. 2014. Virulence structure of the powdery mildew (Blumeria graminis) population occurring on Triticale $(\times$ Triticosecale) in Poland. J. Phytopathol. 162:499-512.

Frantzeskakis, L., Kracher, B., Kusch, S., Yoshikawa-Maekawa, M., Bauer, S., Pedersen, C., Spanu, P. D., Maekawa, T., Schulze-Lefert,
P., and Panstruga, R. 2018. Signatures of host specialization and a recent transposable element burst in the dynamic one-speed genome of the fungal barley powdery mildew pathogen. BMC Genomics 19: 381.

Hew̌itt, T., Mueller, M. C., Molnár, I., Mascher, M., Holušová, K., Šimková, H., Kunz, L., Zhang, J., Li, J., Bhatt, D., Sharma, R., Schudel, S., Yu, G., Steuernagel, B., Periyannan, S., Wulff, B., Ayliffe, M., McIntosh, R., Keller, B., Lagudah, E., and Zhang, P. 2021. A highly differentiated region of wheat chromosome 7AL encodes a Pmla immune receptor that recognises its corresponding AvrPmla effector from Blumeria graminis. New Phytol. 229:2812-2826.

Hurni, S., Brunner, S., Buchmann, G., Herren, G., Jordan, T., Krukowski, P., Wicker, T., Yahiaoui, N., Mago, R., and Keller, B. 2013. Rye Pm8 and wheat $P m 3$ are orthologous genes and show evolutionary conservation of resistance function against powdery mildew. Plant J. 76:957969.

Kowalczyk, K., Gruszecka, D., Nowak, M., and Lesniowska-Nowak, J. 2011. Resistance of triticale hybrids with Pm4b and Pm6 genes to powdery mildew. Acta Biol. Cracov. Ser. Bot. 53:57-62.

Kurtz, S., Phillippy, A., Delcher, A. L., Smoot, M., Shumway, M., Antonescu, C., and Salzberg, S. L. 2004. Versatile and open software for comparing large genomes. Genome Biol. 5:R12.

Li, J., Cornelissen, B., and Rep, M. 2020. Host-specificity factors in plant pathogenic fungi. Fungal Genet. Biol. 144:103447.

Marston, A. L., and Amon, A. 2004. Meiosis: Cell-cycle controls shuffle and deal. Nat. Rev. Mol. Cell Biol. 5:983-997.

Mascher, F., Reichmann, P., and Schori, A. 2006. Einfluss des Mehltaus auf den Triticaleanbau. AGRAR Forschung 13:500-504.

McNally, K. E., Menardo, F., Lüthi, L., Praz, C. R., Müller, M. C., Kunz, L., Ben-David, R., Chandrasekhar, K., Dinoor, A., Cowger, C., Meyers, E., Xue, M., Zeng, F., Gong, S., Yu, D., Bourras, S., and Keller, B. 2018. Distinct domains of the AVRPM3 ${ }^{\mathrm{A} 2 / \mathrm{F} 2}$ avirulence protein from wheat powdery mildew are involved in immune receptor recognition and putative effector function. New Phytol. 218:681-695.

Menardo, F., Praz, C. R., Wicker, T., and Keller, B. 2017. Rapid turnover of effectors in grass powdery mildew (Blumeria graminis). BMC Evol. Biol. 17:223.

Menardo, F., Praz, C. R., Wyder, S., Ben-David, R., Bourras, S., Matsumae, H., McNally, K. E., Parlange, F., Riba, A., Roffler, S., Schaefer, L. K., Shimizu, K. K., Valenti, L., Zbinden, H., Wicker, T., and Keller, B. 2016. Hybridization of powdery mildew strains gives rise to pathogens on novel agricultural crop species. Nat. Genet. 48:201-205.

Müller, M. C., Kunz, L., Schudel, S., Kammerecker, S., Isaksson, J., Wyler, M., Graf, J., Sotiropoulos, A. G., Praz, C. R., Wicker, T., Bourras, S., and Keller, B. 2021. Standing genetic variation of the AvrPm17 avirulence gene in powdery mildew limits the effectiveness of an introgressed rye resistance gene in wheat. bioRxiv.

Müller, M. C., Praz, C. R., Sotiropoulos, A. G., Menardo, F., Kunz, L., Schudel, S., Oberhänsli, S., Poretti, M., Wehrli, A., Bourras, S., Keller, B., and Wicker, T. 2019. A chromosome-scale genome assembly reveals a highly dynamic effector repertoire of wheat powdery mildew. New Phytol. 221:2176-2189.

Oettler, G. 2005. The fortune of a botanical curiosity-Triticale: Past, present and future. J. Agric. Sci. 143:329-346.

Parlange, F., Roffler, S., Menardo, F., Ben-David, R., Bourras, S., McNally, K. E., Oberhaensli, S., Stirnweis, D., Buchmann, G., Wicker, T., and Keller, B. 2015. Genetic and molecular characterization of a locus involved in avirulence of Blumeria graminis $\mathrm{f}$. $\mathrm{sp}$. tritici on wheat Pm3 resistance alleles. Fungal Genet. Biol. 82:181192.

Praz, C. R., Bourras, S., Zeng, F., Sánchez-Martín, J., Menardo, F., Xue, M., Yang, L., Roffler, S., Böni, R., Herren, G., McNally, K. E., Ben-David, R., Parlange, F., Oberhaensli, S., Flückiger, S., Schäfer, L. K., Wicker, T., Yu, D., and Keller, B. 2017. AvrPm2 encodes an RNase-like avirulence effector which is conserved in the two different specialized forms of wheat and rye powdery mildew fungus. New Phytol. 213:1301-1314.

Praz, C. R., Menardo, F., Robinson, M. D., Müller, M. C., Wicker, T., Bourras, S., and Keller, B. 2018. Non-parent of origin expression of numerous effector genes indicates a role of gene regulation in host adaption of the hybrid triticale powdery mildew pathogen. Front. Plant Sci. 9:49.

Singh, S. P., Hurni, S., Ruinelli, M., Brunner, S., Sánchez-Martín, J., Krukowski, P., Peditto, D., Buchmann, G., Zbinden, H., and Keller, B. 2018. Evolutionary divergence of the rye $P m 17$ and $P m 8$ resistance genes reveals ancient diversity. Plant Mol. Biol. 98:249-260. 
Stukenbrock, E. H. 2016. The role of hybridization in the evolution and emergence of new fungal plant pathogens. Phytopathology 106:104-112.

Thines, M. 2019. An evolutionary framework for host shifts - jumping ships for survival. New Phytol. 224:605-617.

Troch, V., Audenaert, K., Bekaert, B., Höfte, M., and Haesaert, G. 2012. Phylogeography and virulence structure of the powdery mildew population on its 'new' host triticale. BMC Evol. Biol. 12:76.
Troch, V., Audenaert, K., Vanheule, A., Bekaert, B., Höfte, M., and Haesaert, G. 2013. Evaluation of resistance to powdery mildew in triticale seedlings and adult plants. Plant Dis. 97:410-417.

Walker, A. S., Bouguennec, A., Confais, J., Morgant, G., and Leroux, P. 2011. Evidence of host-range expansion from new powdery mildew (Blumeria graminis) infections of triticale ( $\times$ Triticosecale) in France. Plant Pathol. 60:207-220. 